\title{
Engrailed Homeobox Genes Regulate Establishment of the Cerebellar Afferent Circuit Map
}

\author{
Roy V. Sillitoe, ${ }^{1,2}$ Michael W. Vogel, ${ }^{3}$ and Alexandra L. Joyner ${ }^{1}$ \\ ${ }^{1}$ Developmental Biology Program, Sloan-Kettering Institute, New York, New York 10021, ${ }^{2}$ Dominick P. Purpura Department of Neuroscience, Albert \\ Einstein College of Medicine, Bronx, New York 10461, and ${ }^{3}$ Department of Psychiatry, Maryland Psychiatric Research Center, University of Maryland \\ School of Medicine, Baltimore, Maryland 21228
}

The spatial organization of the cerebellar afferent map has remarkable correspondence to two aspects of intrinsic patterning within the cerebellum embodied by a series of lobules and Purkinje cell (PC)-striped gene expression. Using male and female mice, we tested whether the Engrailed (En) homeobox genes are a common genetic substrate regulating all three systems, since they are expressed in spatially restricted domains within the cerebellum and are critical for patterning PC gene expression and foliation. Indeed, we discovered that $E n 1 / 2$ are necessary for the precise targeting of mossy fibers to distinct lobules, as well as their subsequent resolution into discrete parasagittal bands. Moreover, each En gene coordinately regulates afferent targeting and the striped pattern of PC protein expression (e.g., ZebrinII/AldolaseC) independent of regulating foliation. We further found that En1/2, rather than the presence of a full complement of lobules, are critical for generating PC protein stripes and mossy fiber bands, and that PC striped gene expression is determined before afferent banding. Thus, the $E n$ transcription factors not only regulate cerebellum circuit topography, but they also link afferent and efferent neurons precisely enough that alterations in PC protein expression can be used as a read out for underlying defects in circuitry. In summary, our data suggest that En1/2 are master regulators of three-dimensional organization of the cerebellum and coordinately regulate morphology, patterned gene expression, and afferent topography.

\section{Introduction}

The adult cerebellum $(\mathrm{Cb})$ is organized into functional circuits that have spatially ordered afferent projections. Since the finding that expression of many proteins in Purkinje cells (PCs), for example ZebrinII/AldolaseC, is organized into striking parasagittal stripes that are mirrored by afferent activity, a critical question to answer has been whether there is a direct relationship between transcription factors within the $\mathrm{Cb}$ and the organization of the underlying neural circuitry. The $\mathrm{Cb}$ has two major afferent pathways, mossy fibers and climbing fibers, which carry sensory-motor information to the $\mathrm{Cb}$ from diverse regions of the brain and spinal cord (Ito, 2006). Importantly, functionally distinct afferent systems project to specific subsets of lobules along the anterior-posterior (AP) axis (numbered I-X) (Larsell, 1952), and resolve into parasagittal domains in the medial-lateral (ML) axis that mirror the PC parasagittal stripes of protein expression (Apps and Hawkes, 2009). Moreover, imaging and electrophysiological studies have demonstrated that functional activity is organized into parasagittal domains in particular lobules that

Received Feb. 5, 2010; revised May 24, 2010; accepted June 16, 2010.

R.V.S. received supportfrom the Alberta Heritage Foundation For Medical Research. A.L.J. was supported bya grant from Autism Speaks and the National Institutes of Health (MH085726-01). We thank Richard Hawkes, Sandra Blaess, Anamaria Sudarov, Praveen Raju, Grant Orvis, Stewart Anderson, Songhai Shi, and Julia Kaltschmidt for comments.

Correspondence should be addressed to Roy V. Sillitoe, Dominick P. Purpura Department of Neuroscience, Albert Einstein College of Medicine, Bronx, NY10461, E-mail: roy.sillitoe@einstein.yu.edu; or Alexandra L. Joyner, Developmental Biology Program, Sloan-Kettering Institute, 1275 York Avenue, New York, NY 10021, E-mail: joynera@mskcc.org.

DOI:10.1523/JNEUROSCI.0653-10.2010

Copyright $\odot 2010$ the authors $\quad 0270-6474 / 10 / 3010015-10 \$ 15.00 / 0$ correlate spatially with PC gene expression (Chockkan and Hawkes, 1994; Ebner et al., 2005; Wadiche and Jahr, 2005; Schonewille et al., 2006). Although in vitro assays have implicated some extracellular proteins in guiding $\mathrm{Cb}$ afferents, no master regulator of three-dimensional organization of afferent topography has been identified.

One possibility is that a common pathway regulates the patterning of $\mathrm{Cb}$ circuitry, morphology, and PC gene expression, since the afferent topography correlates with the intrinsic subdivisions set down by the lobules and PC parasagittal protein stripes. We hypothesized that a candidate master regulator of spatial cues in the $\mathrm{Cb}$ is the Engrailed (En) homeobox transcription factor family, since it is critical for patterning lobules and PC protein stripes (Kuemerle et al., 1997; Sgaier et al., 2007; Sillitoe et al., 2008; Cheng et al., 2010). Furthermore, En1/2 are among several genes transiently expressed in distinct ML domains beginning around embryonic day (E) 15.5 in the mouse (Millen et al., 1995), and the PCs expressing such genes have a defined fate with respect to adult PC stripes (Sillitoe et al., 2009). In addition, the patterning of lobules and parasagittal PC gene expression is altered independently in some En1/2 mutants, indicating that the En genes regulate the patterning of morphology and PC striped gene expression by distinct processes (Sillitoe et al., 2008). A key question that has not been answered is whether En1/2 also play a role in organizing $\mathrm{Cb}$ circuitry. Importantly, alterations in foliation and/or PC gene expression might then be a useful indicator of underlying defects in circuitry.

We show here using an allelic series of mutant mice that En1/2 act within the $\mathrm{Cb}$ to regulate the correct targeting of three mossy 
fiber systems to particular subsets of lobules, as well as their postnatal resolution into ML bands. Importantly, each En gene has a dominant function in targeting afferents of particular circuits that correlates with the role of each gene in patterning PC gene expression, and not foliation. Moreover, in Gli2 conditional mutants, which have a simplified foliation pattern, both PC protein stripes and afferent topography are properly patterned. Additionally, changes in the patterns of PC protein stripes were found to precede disruptions in afferent topography. Our in vivo genetic data thus demonstrate a key role for En1/2 in establishing topographic connections within the $\mathrm{Cb}$ circuit map, and that $\mathrm{PC}$ protein stripes can be used as a readout of afferent topography.

\section{Materials and Methods}

Mice. All animal studies were carried out under an approved International Animal Care and Use Committee animal protocol according to the institutional guidelines at New York University School of Medicine and Memorial-Sloan Kettering Cancer Center. Two En2 null alleles [hd (Joyner et al., 1991) and $n t d$ (Millen et al., 1994)], three En1 null alleles [hd (Wurst et al., 1994), cre (Kimmel et al., 2000), creER ${ }^{T 1}$ (Sgaier et al., 2005)], and an En1 conditional allele [flox (Sgaier et al., 2007)] were used and genotyped as described. En $1^{\text {cre/+}} ;$ Gli2 $2^{\text {flox/zfd }}$ conditional mutants

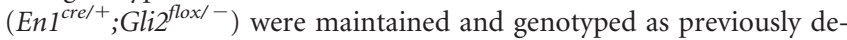
scribed (Corrales et al., 2006). The mutants were kept on an outbred background except for En2 ${ }^{\text {hd }}$ mutants that have been bred to C57BL/6.

Histology and immunohistochemistry. Immunohistochemistry for ML stripe markers was performed as described previously (Sillitoe et al., 2003,2008 ) with the exception of anti-Sst28 (Millipore Bioscience Research Reagents), which was used at 1:1000.

Anterograde tracing. Anterograde tracing of spinocerebellar mossy fibers using wheat germ agglutinin (WGA)-HRP (Sigma) was performed as previously described (Vogel et al., 1996). Note the minor variability in labeling between animals. The variability typically depends on the size of the injection, the amount of tissue damage caused at the injection locus, the capacity of the tissue to recover after surgery, and the efficiency of tracer transport. Despite these variables, which we try to control with standardized injection sizes, carefully controlled delivery of the tracer with finely pulled electrophysiological pipettes, and sterile surgical technique, there was still a modest level of variability in the number of tetramethyl benzidine (TMB; Sigma)-stained axons observed between animals. Substantial variation in labeling arose only after poor injections, which resulted in an almost complete lack of staining. Retrospective analysis of the injection spot confirmed that in most of these cases the injection caused too much tissue damage. Such mice were not included in the final analyses. Injections that showed extensive labeling, but with limited variation in banding patterns observed between animals, suggest that the different patterns of termination arose due to phenotypic differences in En1/2 mutants. Importantly, we recently reported that deletion of En1/2 results in PC stripe patterning defects, which can vary slightly between animals of the same genotype (Sillitoe et al., 2008). Thus, although the basic phenotype is seen in every animal, the overall density of stained afferents can vary. Occasional background staining due to leakage of WGA-HRP into the CSF was observed in the molecular layer after TMB histochemistry (see Fig. $3 d$, white arrows).

Microscopy and data analysis. Photomicrographs were captured using a Retiga SRV camera (QImaging) mounted on a Leica DM6000 microscope. Images were acquired and analyzed using Volocity software (version 4.1.0; PerkinElmer) and thereafter imported into Adobe Photoshop CS2 and Adobe Illustrator CS2.

\section{Results}

In the adult vermis, the expression of many proteins, including ZebrinII/AldolaseC (Brochu et al., 1990; Ahn et al., 1994) and the small heat shock protein Hsp25 (Armstrong et al., 2000), is restricted to distinct patterns of PC parasagittal stripes in four transverse zones along the AP axis (Ozol et al., 1999): the anterior zone (AZ; lobules I-V), the central zone (CZ; lobules VI and VII),

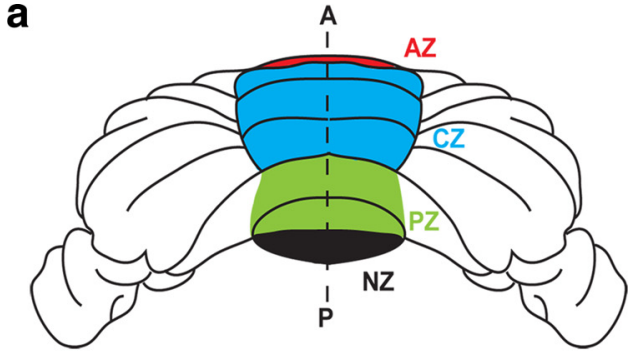

b

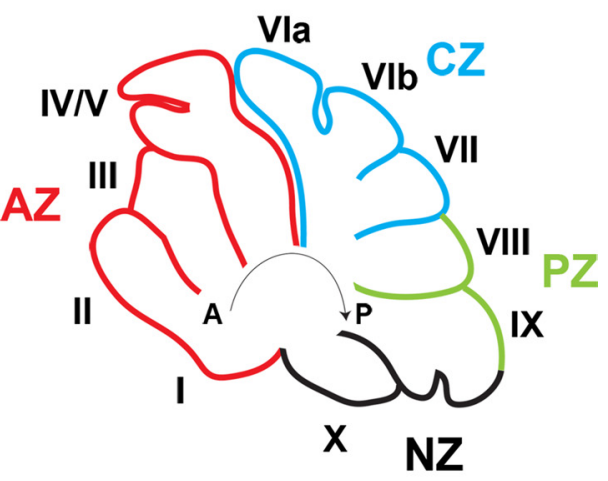

C

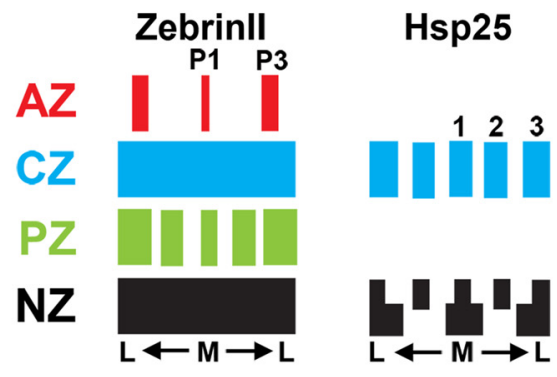

d

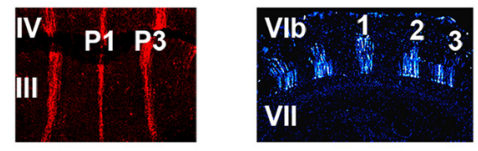

e

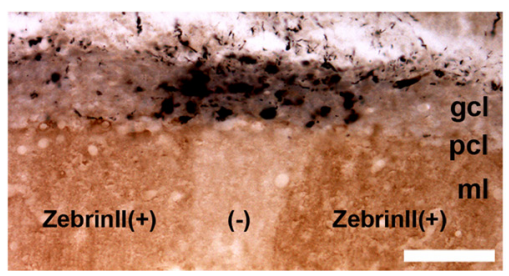

Figure 1. Molecular coding and foliation form a two-coordinate system in the Cb. $\boldsymbol{a}, \boldsymbol{b}$, Gene expression domains in the ML axis divide the 10 lobules into four AP transverse zones. Lobules I-V (red) constitute the AZ, lobules VI-VII (blue) the CZ, lobules VIII-anterior IX (green) the PZ, and lobules posterior IX-X (black) the NZ. c, The ML patterns of Zebrinll and Hsp25 uniquely identify each transverse zone. $\boldsymbol{d}$, Examples of Zebrinll (AZ) and Hsp25 (CZ) ML stripe patterns in the adult mouse Cb.e , Double labeling for Zebrinll (brown, diaminobenzidine) and WGA-HRP (black, nickel-enhanced TMB signal) in lobule VIII of an $E n 1^{\text {flox/cre }}$ mouse showing the common ground plan of PC stripes and spinocerebellar mossy fiber bands in the Cb. Note that Zebrinll expression is restricted to $\mathrm{PC}$ somata in the Purkinje cell layer ( $\mathrm{pcl}$ ) and dendrites in the molecular layer ( $\mathrm{ml}$ ), whereas mossy fibers terminate exclusively within the granule cell layer ( $\mathrm{gcl}$ ). In all figures, lobules are indicated by Roman numerals and the stripe nomenclature was previously described (Brochu et al., 1990; Armstrong et al., 2000).A, Anterior; $P$, posterior; $M$, medial; L, lateral. Scale bar: $e, 50 \mu \mathrm{m}$.

the posterior zone [PZ; lobules VIII, anterior (a) IX], and the nodular zone [NZ; lobules posterior (p) IX, X] (Fig. 1b-d). Importantly, although PC stripe gene expression is most widely studied, gene expression in $\mathrm{Cb}$ cortical interneurons and axon 

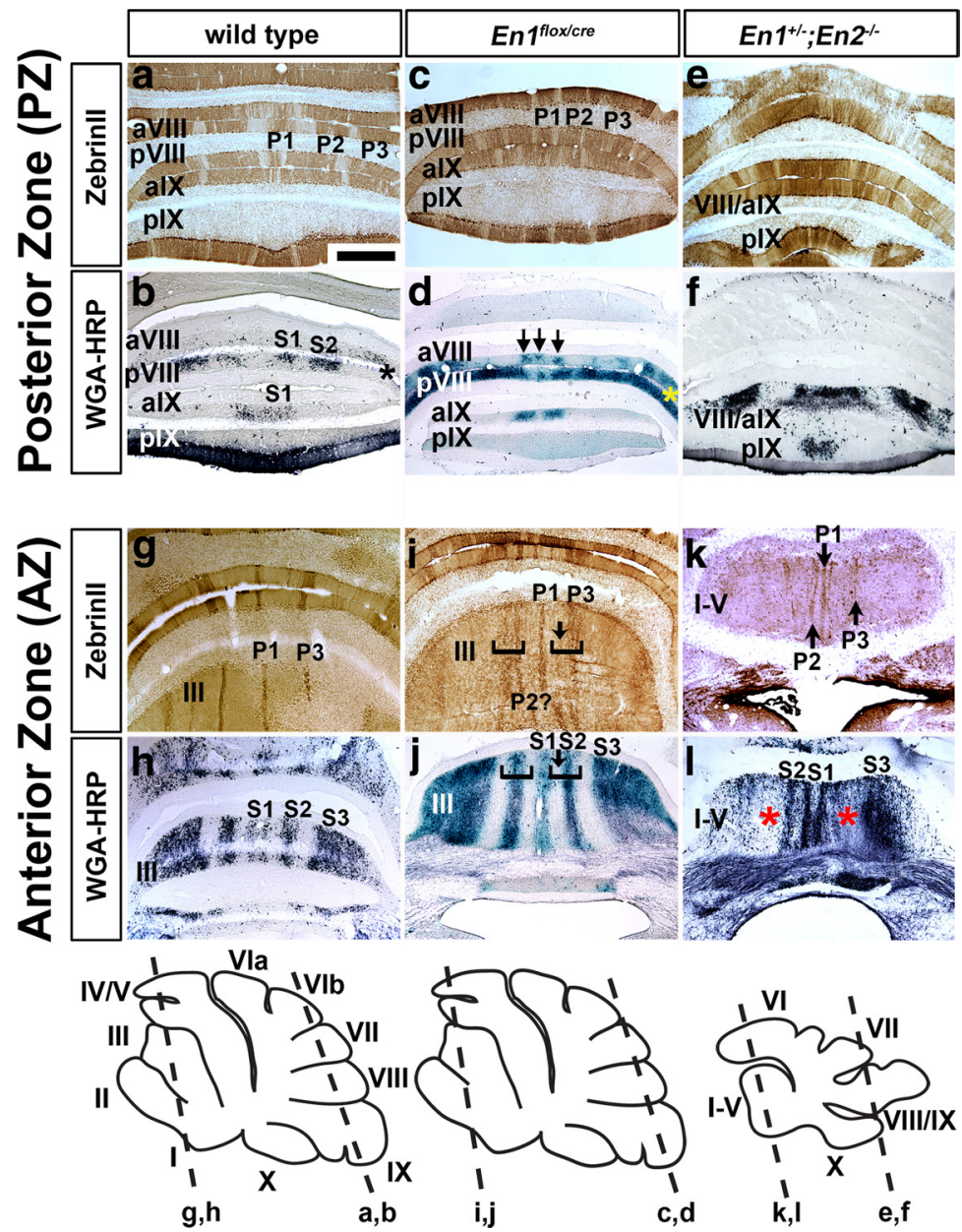

Figure 2. ML topography of spinocerebellar mossy fibers is severely disrupted in En $1 / 2$ mutants. $\boldsymbol{a}, \boldsymbol{c}, \boldsymbol{e}$, Zebrinll stripes are severely altered in the PZ of En mutant mice. $\boldsymbol{b}, \boldsymbol{d}, \boldsymbol{f}$, Spinocerebellar mossy fiber topography is disrupted in the $\mathrm{PZ}$ of $E n 1 / 2$ mice and is correlated with changes in molecular coding. $\boldsymbol{d}$, In En $7^{\text {flox/cre }}$ mutant mice lobule aVIII contains several small clusters (arrows), and the dense staining in pVIII disrupts the clear banding pattern. $f, \ln E n 1^{+/-} ; E n 2^{-/-}$mutants, one large mossy fiber terminal field was located at the midline with two large fields located laterally. $\boldsymbol{g}-\boldsymbol{I}$, Topographical changes in the ML mossy fiber pattern in the $A Z$ of $E n 1^{f l o x / c r e}$ and $E n 1^{+/-} ; E n 2^{-/-}$mutant mice. In $E n 1^{+/-} ; E n 2^{-/-}$mutant mice, bands with ectopic terminals are denoted with red asterisks $(I)$. The brackets in $i$ and $j$ indicate the limits of $S 2$, and the arrow points to the thinner Zebrinll and matching $S 2$ band in $E n 7^{\text {flox/cre }}$ mice. The arrows in $\boldsymbol{k}$ point to the fragmented P1 + to P3 + Zebrinll stripes in $E n 1^{+/-} ; E n 2^{-/-}$ mice. The dotted lines on the sagittal schematics indicate the level of where the coronal tissue sections were taken from. Lobules are indicated by Roman numerals. Scale bar: $\boldsymbol{a}($ for $\boldsymbol{a}-\boldsymbol{i}), 500 \mu \mathrm{m}$.

tracts has been shown to share a common topography with PCs (Apps and Hawkes, 2009). Adult parasagittal gene expression as a whole thus provides a molecular code for the spatial organization of the $\mathrm{Cb}$ (Sillitoe and Joyner, 2007). In En1/2 double mutants, the adult PC molecular code is disrupted in all four zones; whereas, the lobules are preferentially lost in the AZ and PZ (Sgaier et al., 2007; Sillitoe et al., 2008; Cheng et al., 2010). In addition, whereas En 2 is dominant over En1 in patterning the lobules, En1 plays a dominant role in patterning the molecular code in the AZ and PZ (Sgaier et al., 2007; Sillitoe et al., 2008). Thus, the En genes can regulate patterning of lobule morphology and molecular coding by separate processes. In the following experiments, we use genetic approaches to determine whether En1/2 also play a role in organizing $\mathrm{Cb}$ circuitry.

\section{En1/2 regulate $\mathrm{ML}$ afferent topography in the $\mathrm{Cb}$}

As a first approach to test whether afferent topography is dependent on molecular coding and/or foliation processes regulated by En1/2, we analyzed mossy fiber topography in En $1^{\text {flox/cre }}$ condi- tional mutants, which lack En1 function after E9, as they have normal morphology but disrupted molecular coding in the AZ (Fig. 2a,c,e) and PZ (Fig. 2g,i,k) (Sgaier et al., 2007; Sillitoe et al., 2008). We began by examining the spinocerebellar mossy fiber system, since it projects only to the AZ and PZ in the vermis. Mossy fibers that originate from the spinal cord terminate as large synaptic glomeruli in specific ML bands that align with ZebrinII PC stripes in the AZ and PZ (Vogel et al., 1996; Apps and Hawkes, 2009). Axon collaterals project between the two zones and respect the same fundamental band pattern as the primary mossy fibers (Heckroth and Eisenman, 1988). Strikingly, the banded organization of the spinocerebellar terminal field was disrupted in both the AZ and $\mathrm{PZ}$ of En1/2 mutants, and the degree of alterations correlated with changes in the molecular code. In the PZ vermis of wildtype (WT) mice, two pairs of afferent bands (S1 and S2) (Fig. 2b) are located on either side of the midline in the posterior part of lobule VIII (pVIII), and there is only one pair $(\mathrm{S} 1)$ on the anterior face of IX (aIX). In contrast, in lobule pVIII/aIX of En1 $1^{\text {flox/cre }}$ mutants the topography of mossy fibers was drastically altered, with a midline band and many ectopic terminals located throughout the lobule. Strikingly, the lack of pattern correlated with the diffuse stripes of ZebrinII expression in pVIII (Sillitoe et al., 2008) (Fig. 2c). Curiously, in aVIII of En flox/cre mutants three narrow but reproducible $(n=8 / 8)$ mossy fiber bands occupied the midline (Fig. $2 d$, arrowheads), compared with only a few scattered spinocerebellar terminals in controls (Fig. 2b). Although the pattern was reproducible between mutants $(n=$ $8 / 8)$, the intensity of labeling differed (compare Fig. $2 d$, supplemental Fig. $2 h$, available at www.jneurosci.org as supplemental material), likely due to differences in the efficiency of WGA-HRP transport. Interestingly, this gain of mossy fiber patterning in aVIII correlates with ZebrinII expression having a more complex pattern in aVIII of En $1^{\text {flox/cre }}$ mutants compared with WT mice (Sillitoe et al., 2008). In addition, ectopic terminals densely populated the hemisphere extension of lobule VIII (copula pyramidis), where fewer spinocerebellar mossy fibers normally project (Fig. $2 b$, black asterisk; Fig. $2 d$, yellow asterisk; supplemental Fig. $2 h$, available at www.jneurosci.org as supplemental material, arrows).

In the AZ of WT mice, spinocerebellar mossy fibers terminate in one midline (S1) and two adjacent symmetrical pairs of bands (S2 and S3) (Fig. 2h). In En1 $1^{\text {flox/cre }}$ mutants $(n=8)$, the S1 band was weakly stained and the S2 band was often wider than in WT mice (Fig. $2 j$ ). The presence of a wider S2 band always correlated with the presence of an ectopic ZebrinII stripe (Fig. 2i,j) (Sillitoe et al., 2008). Thus, in $E n 1^{\text {flox/cre }}$ mutants, even though the morphology and size of the $\mathrm{Cb}$ are largely normal, the ML topography of mossy fiber bands is disrupted, and the degree of disruption 
correlates with the degree of molecular code defects. In addition, in the $\mathrm{PZ}$ of the vermis the limits of the projection domain ectopically expanded anteriorly and laterally.

$E n 2^{-/-}$mice have only mild defects in spinocerebellar mossy fiber organization (data not shown) (Vogel et al., 1996) and subtle changes in ZebrinII expression (Sillitoe et al., 2008). We tested whether En1/2 together regulate ML mossy fiber topography by analyzing $E n 1^{+/-} ; E n 2^{-/-}$ mutants. Indeed, mossy fiber topography was markedly altered in what remained of the lobules in the $\mathrm{AZ}$ of $E n 1^{+/-} ; E n 2^{-/-}$ mice $(n=6)$. The midline pair of bands (S1) in En $1^{+/-} ; E n 2^{-/-}$mutants was more heavily deposited with WGA-HRP than normal (Fig. $2 l$ ), and the interbands contained many terminals (Fig. $2 l$, red asterisks; supplemental Fig. 1 $i$, available at www.jneurosci.org as supplemental material). In addition, whereas in lobules I-III of the AZ in WT mice S1 was less dense than S2 (Fig. $2 h$ ), the reverse was found in the AZ of $E n 1^{+/-} ; E n 2^{-/-}$mutant mice such that $S 1$ was substantially denser and wider than S2 (Fig. 2l; supplemental Fig. $1 i$, available at www.jneurosci. org as supplemental material). In the $\mathrm{PZ}$ of $E n 1^{+/-} ; E n 2^{-/-}$mutant mice where lobule VIII is greatly reduced, one wide medial band and two lateral bands replaced the normal two lateral pairs of bands (Fig. $2 f$ ). As in the AZ, the intensity of HRP histochemical staining, and thus likely the density of terminals, was increased in $E n 1^{+/-} ; E n 2^{-/-}$ mutant mice compared with WT mice (Fig. $2 f$, lobule VIII/aIX). In summary, the disrupted mossy fiber topography reflected the altered ZebrinII molecular coding with fragmentation in the AZ (Fig. $2 k, l)$ and fused midline mossy fiber bands in the PZ (Fig. 2e,f).

To further probe how En1 and En2 together regulate afferent topography, we analyzed En1/2 single and double heterozygotes. We found that, similar to molecular coding, afferent topography was more sensitive than foliation to the dosage of En1/2 (Fig. 3; supplemental Fig. 1, available at www.jneurosci.org as supplemental material), as $E n 1^{+/-}$mice had mild, but consistent defects in the $\mathrm{AZ}$ and $\mathrm{PZ}$ (Fig. 3e, arrow; $3 f$, red brackets and asterisk), and $E n 2^{+/-}$mice in the PZ. Moreover, the severity of afferent targeting defects increased in the allelic series in the same order as ML molecular coding defects: $E n 2^{+/-}<E n 1^{+/-}<E n 2^{-/-}<$ $E n 1^{+/-} ; E n 2^{+/-}<E n 1^{\text {flox/cre }}<E n 1^{+/-} ; E n 2^{-/-}$mutant mice (Fig. 3; supplemental Fig. 1, available at www.jneurosci.org as supplemental material).

\section{A reduction in the number of lobules does not necessarily disrupt mossy fiber topography}

One possible contribution to the disruption of afferent patterning in $E n 1^{+/-} ; E n 2^{-/-}$mutants is the smaller $\mathrm{Cb}$ and thus reduced target field. To test whether a reduction in lobules necessarily leads to a disruption of mossy fiber topography, we examined afferent topography in $\mathrm{En1}^{\text {cre/+ }} ; \mathrm{Gli2}^{\text {flox/- }}$ conditional knock-out mutants, which have an approximately one-third reduction in the size of the $\mathrm{Cb}$. Gli2, a transcription factor post-translationally regulated by Sonic hedgehog (Shh) signaling, is expressed in the Cb beginning at $\sim$ E15.5 in all cells but the PCs that express Shh (Corrales et al., 2004). In En ${ }^{\text {cre/+ }}$; Gli2 $2^{\text {flox/- }}$ mice granule cell proliferation is reduced, and the foliation pattern resembles an immature postnatal day (PD) 2 WT Cb with only five major folds (Corrales et al., 2006). Thus, patterning of the lobules can be considered normal, but $\mathrm{Cb}$ development is halted prematurely.

We first analyzed molecular coding in $\mathrm{EnI}^{\mathrm{cre} /+} ; \mathrm{Gli}^{\text {flox/- }}$ mice ( $n=10)$ to determine whether it was also normal. Indeed, the expression patterns of ZebrinII (Fig. $4 a, c, e, g$ ) and Hsp25 (Fig. $4 b, d, f, h)$ were found to be normal in the AZ/PZ and CZ/NZ, respectively. Thus, dramatic defects in lobule morphogenesis do not necessarily impact the formation of a normal molecular code.

Correlating with the normal PC stripes, five clear ML spinocerebellar mossy fiber bands were detected in the $\mathrm{AZ}$ of $E n 1^{\text {cre/+}}$; Gli2 $2^{\text {flox } /-}$ mice $(n=10)$ with no increase in terminals between bands (Fig. $3 a, g$ ). Like $E n 1^{+/-}$controls, the S1 band had a reduced number of mossy fiber terminals (Fig. $3 e$, white arrow; Fig. $3 g$, black arrow). In lobule pVIII of the PZ (Fig. $3 h$ ), the pattern also resembled $E n 1^{+/-}$controls $(n=4)$ (Fig. $3 f$ ) with one wide midline mossy fiber band replacing the normal two bands (Fig. $3 b) . E n 1^{\text {cre/+ }} ; G l i 2^{\text {flox/- }}$ mutants also had a similar pattern to the controls in aIX (Fig. 3f,h). Finally, En1 ${ }^{\text {cre/+ }} ; G l i 2^{\text {flox/- }}$ mutants like $E n 1^{+/-}$controls had ectopic terminals in the copula pyramidis (Fig. $3 f$, red arrow; Fig. $3 h$, inset, white arrow). Thus, decreasing 

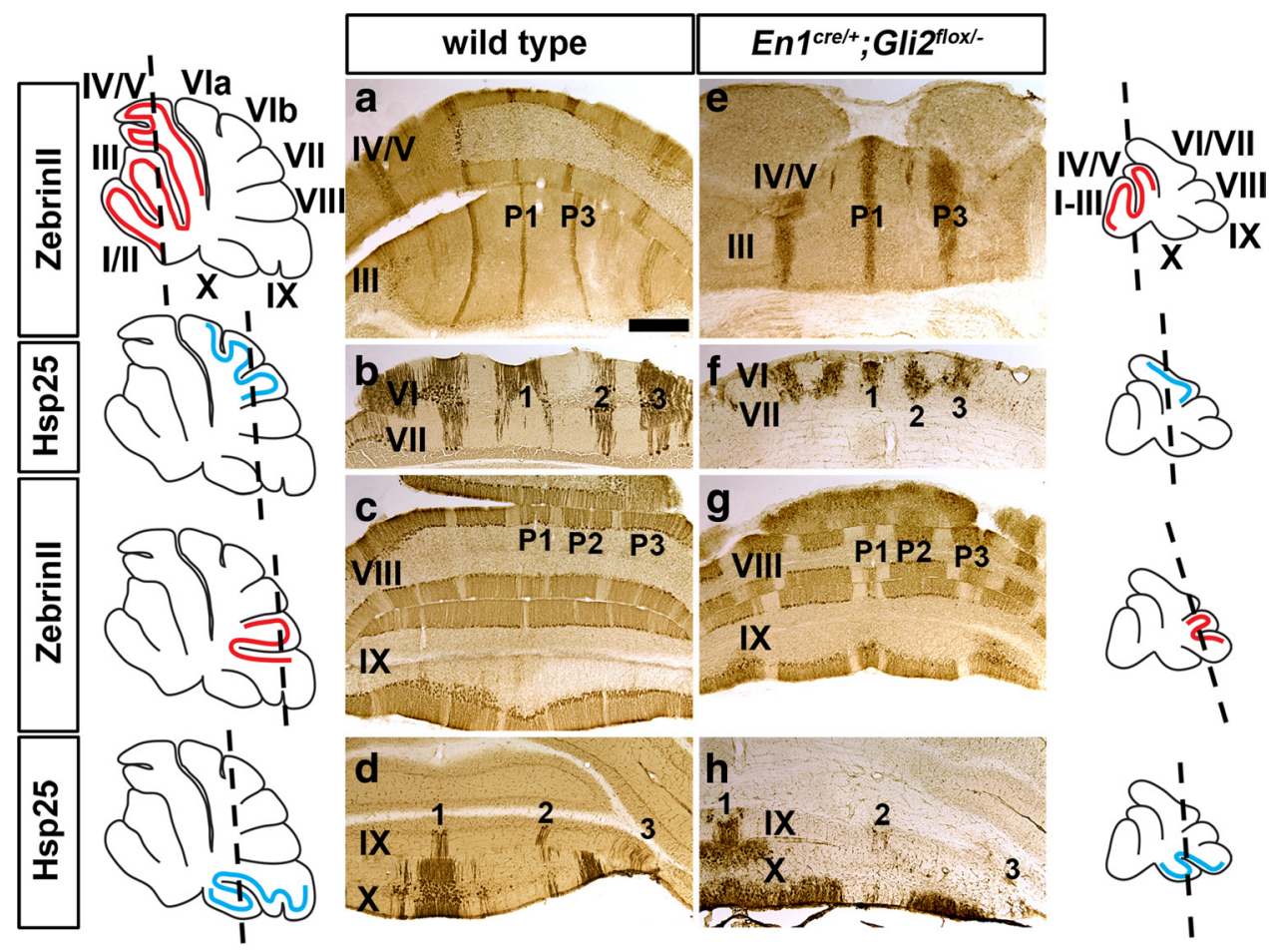

Figure 4. Molecular coding is normal in En $7^{\text {cre/+ }} ;$ Gli2 ${ }^{\text {flox/ }-}$ mutant mice. $\boldsymbol{a}-\boldsymbol{d}$, Zebrinll molecular coding as seen on coronal cut tissue sections in the AZ (a) and PZ (c), and Hsp25 molecular coding in the CZ $(\boldsymbol{b})$ and NZ $(\boldsymbol{d}) \cdot \boldsymbol{e}-\boldsymbol{h}$, Zebrinll $(\boldsymbol{e}, \boldsymbol{g})$ and Hsp25 $(\boldsymbol{f}, \boldsymbol{h})$ molecular coding is normal in all four transverse zones in En ${ }^{\text {cre/+ }} ;$ Gliz $^{\text {ffox/- }}$ mutant mice. The sagittal schematics on the left (WT) indicate the lobules that show parasagittal stripes of Zebrinll (red) and Hsp25 (blue), and correspond to the tissue sections shown in $\boldsymbol{a}-\boldsymbol{d}$. The sagittal schematics on the right (En $1^{\text {cre/ }+}$; Gli2 ${ }^{\text {flox/- }}$ ) indicate the lobules that show parasagittal stripes of Zebrinll (red) and Hsp25 (blue), and correspond to the tissue sections shown in $\boldsymbol{e}-\boldsymbol{h}$. The dotted lines on the sagittal schematics indicate the level from which the coronal tissue sections were taken. Scale bar: $\boldsymbol{a}($ for $\boldsymbol{a}-\boldsymbol{h}), 500 \mu \mathrm{m}$.

Shh/Gli signaling in the $\mathrm{Cb}$ and dramatically reducing the size of the $\mathrm{Cb}$ does not alter the basic ML topography of spinocerebellar afferents or molecular coding.

\section{$E n 1 / 2$ are required to restrict afferent termination into distinct AP domains}

The presence of ectopic terminals in aVIII in En $1^{\text {flox/cre }}$ mutants raised the question of whether En1/2 regulate targeting of mossy fibers in the AP dimension, in addition to their clear role in ML targeting. Consistent with this idea, in the posterior $\mathrm{Cb}$ of $E n 1^{+/-}$; $E n 2^{-/-}$mutants spinocerebellar afferents projected ectopically not only into lobule aVIII, but also into a more posterior region of aIX than normal (Fig. $5 c-e$, brackets). A similar, but milder, posterior expansion of the $\mathrm{PZ}$ terminal domain also was observed in En1 $1^{\text {flox/cre }}$ mice (Fig. 2b,d; supplemental Fig. 1h, available at www.jneurosci.org as supplemental material). Moreover, in both mutants the expansion of terminal fields in the AP axis correlated with an expansion of molecular patterning (Fig. 5i,k). Furthermore, in the anterior vermis of $E n 1^{+/-} ; E n 2^{-/-}(n=4)$ (Fig. $5 b, e, h$ ), but not En1 flox/cre (data not shown) mutant mice the spinocerebellar mossy fiber termination field expanded posteriorly into the anterior face of lobule VI (Fig. $5 f-h$, bracket). In addition, in lobule VIa of $E n 1^{+/-} ; E n 2^{-/-}$mutants, ZebrinII stripes are expanded posteriorly into this region (Fig. $5 i-k$ ) (Sillitoe et al., 2008). Since foliation is normal in the posterior $\mathrm{Cb}$ of En1 ${ }^{\text {flox/cre }}$ mutants (Fig. 2; supplemental Fig. 1, available at www. jneurosci.org as supplemental material) (Sgaier et al., 2007), the expansion of the PZ termination field must be attributed to the loss of $E n 1$ function in afferent patterning and not changes in the number of target neurons. Since $E n 1^{+/-} ; E n 2^{-/-}$mutants have fewer lobules, one possibility was that afferents misproject outside their termination field in these mutants due to the overall reduction in the size of their target field, rather than guidance being altered as reflected by abnormal molecular coding. If this were the case, then mossy fiber patterning in the AP axis should be more severely affected in $E n 1^{\text {cre/+}} ;$ Glifflox/- mutants than in $E n 1^{+/-} ; E n 2^{-/-}$mice. Contrary to this prediction, the AP patterning of spinocerebellar afferents was more severely affected in $E n 1^{+/-} ; E n 2^{-/-}$mice (Fig. 5). These results argue that the size of the $\mathrm{Cb}$ in $E n 1^{+/-} ; E n 2^{-/-}$mutants does not account for the extensive mistargeting of afferents to adjacent lobules, but instead En1/2 regulate mossy fiber topography in the AP orientation, in addition to the ML orientation.

\section{En1/2 are required for orchestrating the development of multiple sensory maps}

$E n 2^{-l-}$ mice have subtle defects in spinocerebellar mossy fiber topography (Vogel et al., 1996). However, given that both molecular coding and afferent topography defects were detected in lobule VIII of the PZ, which has abnormal foliation, it was not clear whether the circuitry defects were secondary to foliation. To determine whether En1/2 play a broad role in regulating mossy fiber topography, we analyzed the CZ and NZ topography of a subset of mossy fibers that project from the pontine and vestibular nuclei, and express Somatostatin28 (Sst28) (Yacubova and Komuro, 2002). In WT mice, Sst28 marked distinct subsets of mossy fiber terminals in the internal granular layer (IGL) of lobules pIX and X (the vestibulocerebellar domain) (Figs. 6a, 7b) (Armstrong et al., 2009) and lobules VIb and VII (the pontocerebellar domain) (Fig. 7a). Although a clear ML Sst28 pattern was not observed in the CZ, in $\mathrm{pX}$ of the NZ four clear ML bands of Sst28 were present: one pair on either side of 
the midline (Fig. $6 a$, rectangle and arrow) and an additional pair at the lateral edges (data not shown) (Armstrong et al., 2009). Double immunostaining in WT mice for choline acetyltransferase, which in the vermis marks vestibular mossy fibers that project mainly to the NZ (Barmack et al., 1992; Sillitoe et al., 2003), showed that $\sim 50 \%$ of the Sst 28 immunoreactive terminals in the NZ likely belong to mossy fibers of the vestibulocerebellar tract (supplemental Fig. 2, available at www.jneurosci.org as supplemental material).

In mutants lacking $E n 1(n=8)$, there was a substantial reduction in the number of immunostained terminals in each NZ band (Fig. 6b, white rectangle). Conversely, in $E n 2^{-/-}$(Fig. $6 c$, arrow) $(n=8)$ and $E n 1^{+/-} ; E n 2^{-/-}$(data not shown; $n=$ 8) mutants, ectopic terminals were located at the midline, producing a uniform domain across the midline. In sagittal sections, it was apparent that the NZ domain was shifted posteriorly in $E n 2^{-/-}(n=4)$ and $E n 1^{+/-} ; E n 2^{-/-}(n=4)$ mutants (Fig. $7 f, h$, arrows). As in the NZ, the number of terminals in the $\mathrm{CZ}$ of En1 $1^{\text {flox/cre }}$ mutants $(n=4)$ was severely reduced (Fig. $7 a-d)$, but the number of terminals in $\mathrm{EnI}^{+/-}$; $E n 2^{-/-}$mutants was also reduced (Fig. $7 \mathrm{~g}$ ). In $E n 2^{-/-}$mutants, the number of terminals was not greatly reduced in the $\mathrm{CZ}$ domain (Fig. 7e), but the domain appeared slightly expanded anteriorly (Fig. 7, compare $a$ and $e$, positions of arrows; supplemental Fig. 3, available at www. jneurosci.org as supplemental material, arrows). We also observed scattered Sst28immunoreactive terminals in the IGL of the anterior face in lobule VIa (Fig. 7e, arrowheads; supplemental Fig. 3, available at www.jneurosci.org as supplemental material, arrowheads). We observed very little variability in the staining pattern of Sst 28 between animals of the same genotype, and we therefore attribute any differences in mossy fiber patterning to each phenotype. Together, these results demonstrate that En1 and En2 regulate different aspects of development of multiple mossy fiber systems that send sensory information to distinct AP and ML zones. Moreover, the AP and ML patterning defects in mossy fiber topography in the $\mathrm{CZ} / \mathrm{NZ}$ of $E n 2^{-/-}$mice are accompanied by disruptions in the molecular code (Hsp25) (Sillitoe et al., 2008).

\section{En1/2 are required for patterned axon regression postnatally} after molecular coding is established

En1/2 could be required to establish the specific ML band patterns of mossy fibers, or to maintain properly patterned topography. To distinguish between these possibilities, we determined the normal process of spinocerebellar terminal field development and then analyzed the process in $E n 1^{+/-} ; E n 2^{-/-}$mice as they have the most disrupted patterns in the AZ and PZ. Spinocerebellar mossy fibers enter the mouse $\mathrm{Cb}$ at approximately E13/14 (Grishkat and Eisenman, 1995). Previous studies suggest that the adult band pattern is established by approximately PD7 in rat
(Arsénio Nunes and Sotelo, 1985). At birth, spinocerebellar mossy fibers in WT mice were found to terminate throughout the ML extent of the AZ and PZ (data not shown). By PD3, the fibers still occupied the entire ML extent of the vermis (Fig. $8 a, b$ ). Interestingly, at both PD0 and PD3 mossy fibers were found in more lateral regions than in the adult, including the lateral aspects of the copula pyramidis (Fig. 8b). Subtle indications of heavy versus weak spinocerebellar termination domains were seen in the vermis at PD3 (Fig. $8 a$, asterisks). By PD5, a clear adult banded pattern was seen in the vermis with few terminals persisting in the hemispheres (Fig. 8c,d). Consistent with our analysis of mossy fiber topography in the adult $E n 1^{\text {cre/+}} ; G l i 2^{\text {flox/- }}$ mutants, both the AP and ML patterns of spinocerebellar mossy fibers observed at PD5 were like En1 ${ }^{\text {cre/+ }}$ (data not shown) and WT controls (Fig. $8 c-f$ ). In contrast, in $E n 1^{+/-}$; $E n 2^{-1-}$ mutants the pattern was severely disrupted at PD5 (Fig. $8 g, h)$, and ectopic terminals were found in bands that are normally are devoid of spinocerebellar terminals (Fig. $8 c, e, g$, black arrows). In two of six $E n 1^{+/-} ; E n 2^{-/-}$mutants, no ML bands were apparent at PD5 (data not shown). In the other animals, which had milder foliation defects, a pattern similar to the abnormal adult ML band topography was obvious, including projections throughout the copula 


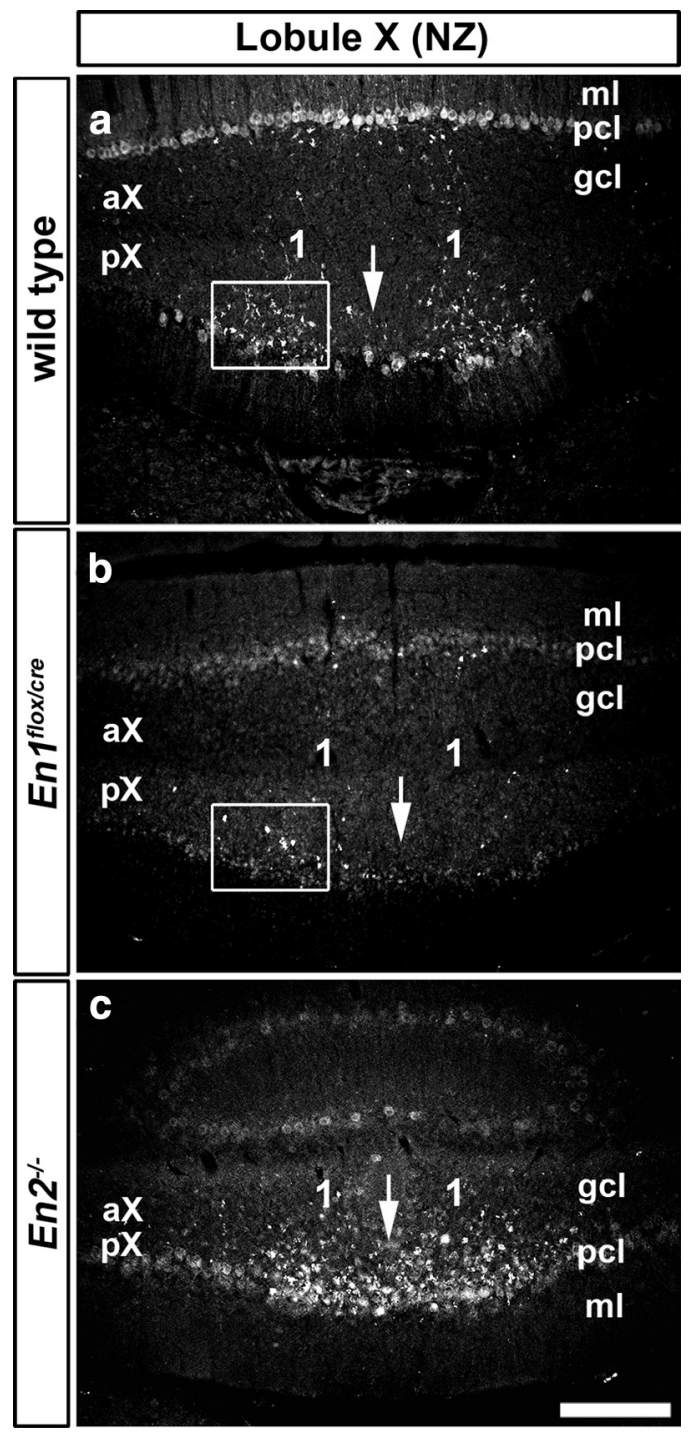

Figure 6. The ML topography of mossy fibers is disrupted in the NZ of Engrailed mutant mice. $\boldsymbol{a}$, Sst28 is expressed in distinct mossy fiber bands in the NZ. Two clusters (numbered as 1) abut the negative midline (arrow). Note that PCs were weakly immunoreactive for Sst28 [see Purkinje cell layer $(\mathrm{pcl})] . \boldsymbol{b}, \boldsymbol{c}, \ln E n 1^{\text {flox/cre }}$ mice $(\boldsymbol{b})$, there are only few mossy fibers that express Sst28 ( $\boldsymbol{a}$ and $\boldsymbol{b}$, compare the staining in the white rectangles), while in En2 $2^{-/-}$mice (c) Sst28 immunoreactive mossy fibers were ectopically located at the midline (arrow). ml, Molecular layer; gcl, granule cell layer. Scale bar: $\boldsymbol{c}($ for $\boldsymbol{a}-\boldsymbol{c}$ ), $250 \mu \mathrm{m}$

pyramidis (Fig. $8 g, h$ ). We also found that at PD5 mossy fibers were ectopically targeted in the AP axis of $E n 1^{+/-} ; E n 2^{-/-}$mutants with a substantial number of mistargeted terminals in lobules VI and posterior lobule IX (data not shown).

Given the correlation between changes in molecular coding and afferent topography in En1/2 mutants, we tested whether the molecular code is changed before PD5 in the mutants. We analyzed phospholipase $\mathrm{C} \beta 4(\mathrm{Pl} \beta 34)$ expression since, unlike ZebrinII or spinocerebellar mossy fibers, it is expressed in a clear pattern of stripes starting at approximately E18 (Marzban et al., 2007). Of additional importance, $\mathrm{Plc} \beta 4$ expression maintains the same configuration of stripes from late embryonic stages through to adulthood (Marzban et al., 2007). Therefore, given that in the mature $\mathrm{Cb}$ stripes of $\mathrm{Plc} \beta 4$ are complementary to stripes of $\mathrm{Ze}$ brinII (Sarna et al., 2006), early postnatal PC protein stripe defects in En1/2 mice would be predicted to correlate to adult protein stripe defects. At PD2 in the AZ, two wide pairs of $\mathrm{Plc} \beta 4$ stripes flank the midline (Marzban et al., 2007) (Fig. 8i). In contrast, at PD2 in $E n 1^{+/-} ; E n 2^{-/-}$mutants the Plc $\beta 4$-negative stripes were narrow and fragmented (Fig. 8j, arrows), and complementary to the ZebrinII pattern observed in $E n 1^{+/-} ; E n 2^{-/-}$ adult mice (Sillitoe et al., 2008). Thus, En1/2 are required for patterning ML molecular coding before establishment of mossy fiber topography, and the initial topographical defects of the spinocerebellar tract mirror the degree of the molecular coding defects.

\section{Discussion}

We previously proposed that the $\mathrm{Cb}$ contains an intrinsic coordinate system that is used to spatially organize cells, axons/dendrites, and gene expression in the AP and ML axes (Sillitoe and Joyner, 2007). We now show that the En transcription factors not only regulate patterning of morphology and molecular coding, but also targeting of mossy fibers within the $\mathrm{Cb}$. Importantly, we observed that by gradually lowering the dose of En1/2 changes in mossy fibers topography mirrored the severity of changes in PC protein stripe gene expression and did not correlate with disruptions of foliation. For example, despite foliation being normal in the $\mathrm{PZ}$ of EnI flox/cre mice, in regions where ZebrinII expression was homogeneous, mossy fibers were targeted into a uniform domain. Moreover, ectopic regions of ZebrinII striped expression in En1 flox/cre or $E n 1^{+/-} ; E n 2^{-/-}$mice were mirrored by AP mistargeting of spinocerebellar terminals into the $\mathrm{CZ}$ and $\mathrm{NZ}$. Importantly, molecular coding changes were seen before development of afferent targeting defects. Thus, our data provide evidence that the molecular code is causally related to guidance cues used by incoming afferents to pattern their topography within the $\mathrm{Cb}$, and can therefore be used as a readout of changes in the underlying circuit map.

Independent genetic support for the conclusion that changes in afferent topography are better reflected by changes in molecular coding than foliation come from our analysis of $E n 1^{\text {cre/+ }}$; Gli2 $2^{\text {flox/ }}$ mice. Surprisingly, we found that regardless of the severe reduction in the target field of mossy fibers in $\mathrm{EnI}^{\mathrm{cre} /+}$; Gli2 $2^{\text {flox/- }}$ mice, an almost normal mossy fiber topography developed in these mutants. Furthermore, the correct afferent targeting in $\mathrm{En1}^{\text {cre/+ }}$; Gli2 $2^{\text {flox/- }}$ mutants was accompanied by normal PC molecular coding. In accordance with our genetic studies in the $\mathrm{Cb}$, ablation and transplantation of the retina and/or tectum in various species have demonstrated that compression and expansion of a target field can result in normally patterned afferent projections (Udin and Fawcett, 1988). From these data, we propose that targeting of $\mathrm{Cb}$ afferents is dependent on guidance cues represented by stripes of proteins in PCs in each transverse zone.

The signals required for initial organization of the PC molecular code are thought to be intrinsic to the $\mathrm{Cb}$. The ML pattern of L7/Pcp2 embryonic gene expression initiates with a normal pattern (albeit delayed) in organ cultures derived from E14 mouse $\mathrm{Cb}$ (Oberdick et al., 1993). In addition, ZebrinI-positive andnegative PCs develop in the absence of afferent inputs when $\mathrm{Cb}$ tissue from E12-E15 rat embryos (before afferents enter the $\mathrm{Cb}$ ) is transplanted ectopically (Wassef et al., 1990). Thus, the availability of patterned gene expression within the embryonic $\mathrm{Cb}$, before the arrival of afferents, provides a means by which afferents could be guided within an existing map, since the map has rudimentary features of the adult topographic circuit (Sillitoe et al., 2009).

Studies of mutant mice that have primary defects in PCs (e.g., Staggerer) versus granule cells (e.g., Weaver) suggested that PCs 
could directly control the topography of developing mossy fibers (Arsénio Nunes et al., 1988). Since mossy fibers initially contact PCs in the embryonic and early postnatal $\mathrm{Cb}$ before synapsing with granule cells (Mason and Gregory, 1984; Manzini et al., 2006), PCs could indeed provide necessary targeting cues required to organize mossy fibers. In accordance with this idea, we found that spinocerebellar afferents do not attain their banded pattern until PD5. Furthermore, in vitro preparations of the embryonic chick hindbrain revealed that $\mathrm{Cb}$-intrinsic molecular cues guide climbing fibers (Chédotal et al., 1997; Nishida et al., 2002; Sotelo and Chédotal, 2005). These results raised the possibility that transcription factors in the $\mathrm{Cb}$ regulate the expression of proteins involved in afferent targeting and formation of the $\mathrm{Cb}$ circuit map. Since En1/2 are expressed in ML domains in developing PCs (data not shown) (Millen et al., 1995; Sgaier et al., 2007), En1/2 could control the expression of PC guidance molecules critical for patterning mossy fiber topography. Consistent with this, we found that in $E n 1^{+/-} ; E n 2^{-/-}$mice the molecular code is disrupted before spinocerebellar afferents attain their mature topography. Given that En1/2 control topographic targeting of retinotectal axons by regulating Eph/ephrin signaling (Logan et al., 1996; Brunet et al., 2005), and EphA4 might be expressed in complementary stripes to En1/2 (Hashimoto and Mikoshiba, 2003), it is tempting to speculate that Eph/ ephrins are critical targets of En1/2 during $\mathrm{Cb}$ circuit formation.

En1/2 expression is dynamic during $\mathrm{Cb}$ development (data not shown) (Millen et al., 1995; Sgaier et al., 2007). Initially, En1/2 mRNA and protein are expressed in the ventricular zone. During late embryonic/ early postnatal $\mathrm{Cb}$ morphogenesis, En1/2 are expressed in spatially restricted patterns in most cell types, including PCs and granule cells. Given that En1/2 have multiple roles during $\mathrm{Cb}$ development (Sgaier et al., 2007; Sillitoe et al., 2008; Cheng et al., 2010), their dynamic expression across multiple cell types might impart specific target populations with the capacity to progressively instruct mossy fiber development. In this scenario, En1/2 could initially regulate the expression of genes in PCs that encode for proteins that shape the overall organization of topographic circuits and later in granule cells regulate cues required for refinement of neural circuit architecture. Although the transient interaction of PCs with mossy fibers likely represents a specific mode of cell-cell communication, transient interactions during circuit formation are not unique to the $\mathrm{Cb}$ (Chao et al., 2009). Subplate neurons in the developing forebrain act as a transient relay between lateral geniculate neurons and the cerebral cortex (Kanold, 2009). As neurons in the cortical layers

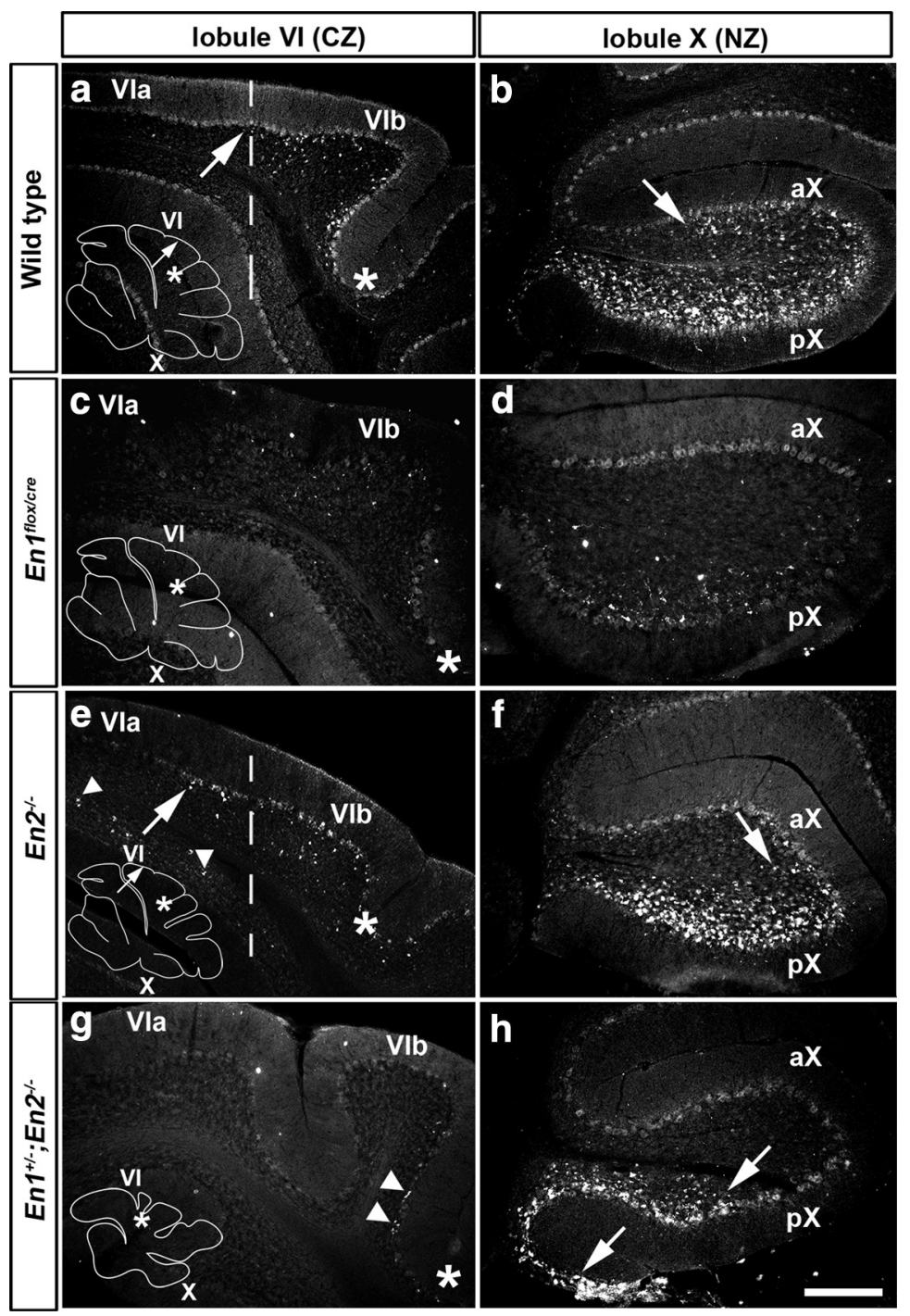

Figure 7. The AP topography of mossy fibers is disrupted in the CZ and NZ of Engrailed mutant mice. $\boldsymbol{a}, \boldsymbol{b}$, Sst28 is predominantly expressed in lobules VIb-VII and IX-X of the mouse Cb. The asterisk in $a$ indicates the fissure between lobule VIb and VII (also true for $\boldsymbol{c}, \boldsymbol{e}$, and $\boldsymbol{g}$ ). The arrows indicate the anterior limits of Sst28 expression in lobule VI. $\boldsymbol{c}, \boldsymbol{d}$, Sst28 expression is dramatically reduced the NZ only a few terminals were found in lobule aX. The dashed white vertical line in $\boldsymbol{a}$ indicates the anterior limit of Sst28 shifted domain). The schematics illustrate the location of Sst28-immunoreactive terminals in lobule VI (CZ) and lobule X (NZ). The arrows in $\boldsymbol{a}$ and $\boldsymbol{e}$ point to the anterior limits of expression in the $\mathrm{CZ}$, and the asterisks indicate the intercrural fissure located between lobules VI and VII. Scale bar: $\boldsymbol{h}$ (for $\boldsymbol{a}-\boldsymbol{h}$ ), $200 \mu \mathrm{m}$.

begin to mature, afferents from the lateral geniculate nucleus extend into the cortex and form stable synapses with their final targets in layer 4 (Kanold, 2009). Thus, in both the cerebral cortex and $\mathrm{Cb}$, transient cell-cell contacts likely provide organizational cues for developing axons before the maturation of their ultimate target cells. Our studies indicate that in the $\mathrm{Cb}, E n 1 / 2$ could coordinately regulate both stages of axon targeting, since they are expressed in PCs and granule cells.

Our finding that the $\mathrm{Cb}$ molecular code reflects the organization of $\mathrm{Cb}$ circuitry has important implications for understanding human neurological diseases. Human EN2 is one of several susceptibility loci in autism spectrum disorder (ASD) (Gharani et 

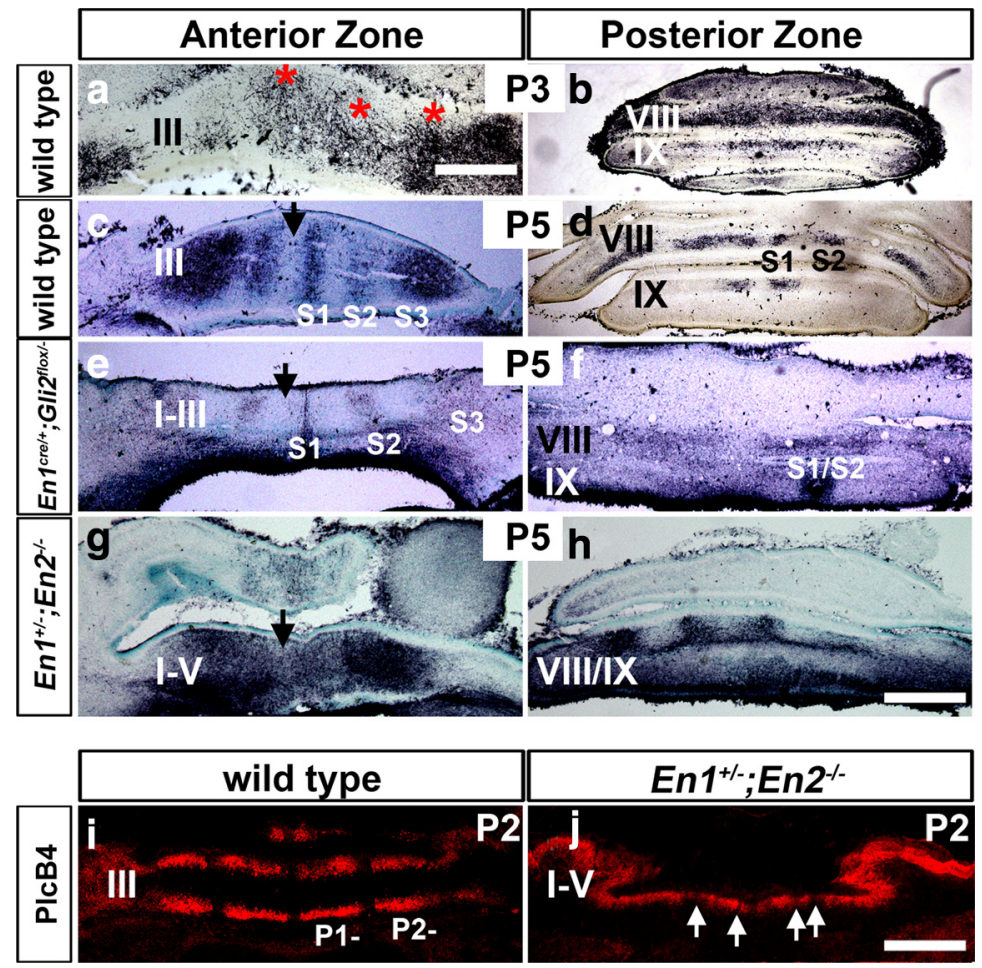

Figure 8. Spinocerebellar mossy fibers resolve into a ML banded pattern during the first postnatal week. $\boldsymbol{a}, \boldsymbol{b}$, WGA-HRP anterograde tracing of the spinocerebellar tract at PD3 reveals terminals in the lobules I-V (AZ) and VIII/IX (PZ) as seen on a coronal section. In the PZ mossy fiber terminals were seen throughout the entire ML extent of lobule VIII, and in the AZ a crude map of bands was observed ( $\boldsymbol{a}$, asterisks). $\boldsymbol{c}, \boldsymbol{d}$, By PD5 a clear ML banded pattern is obvious in the AZ and PZ. $\boldsymbol{e}, \boldsymbol{f}$, The pattern of spinocerebellar bands was normal in the Cb of PD5 En $7^{\text {cre/+ }} ; G$ Gli2 ${ }^{\text {flox/- }}$ mutants. $\boldsymbol{g}, \boldsymbol{h}$, The pattern of spinocerebellar bands was severely disrupted in the Cb of PD5 En1 ${ }^{+/-} ; E n 2^{-/-}$mice, with ectopic terminals located in bands that are normally devoid of spinocerebellar terminals ( $\boldsymbol{c}, \boldsymbol{e}, \boldsymbol{g}$, compare black arrows). $\boldsymbol{i}, \boldsymbol{j}, \ln E n 1^{+/-} ; E n 2^{-/-}$mice, the PC molecular code was disrupted at PD2, before spinocerebellar terminals resolve into bands, as determined by PIc $\beta 4$ expression. Compared with wild-type mice $(i)$, the Plc $\beta 4$ positive stripes in $E n 1^{+/}$;En2 ${ }^{-1-}$ mice were separated by thin negative stripes (j, white arrows). Scale bars: $\boldsymbol{a}, 250 \mu \mathrm{m} ; \boldsymbol{h}$ (for $\boldsymbol{b}-\boldsymbol{g}), 500 \mu \mathrm{m} ; \boldsymbol{j}$ (for $\boldsymbol{i}, \boldsymbol{j}) 500 \mu \mathrm{m}$.

al., 2004; Benayed et al., 2005), and En2 $2^{-/-}$mice display neurobehavioral and neurochemical alterations typically seen in ASD (Cheh et al., 2006). Since we have uncovered that morphological defects are not necessarily associated with circuit changes $\left(E n 1^{\text {cre/+ }}\right.$; Gli2 $^{\text {flox/- }}$ mutants), whereas molecular coding defects are, it should now be possible to predict how topographic maps are altered in complex genetic neurological diseases by analyzing ZebrinII molecular coding in postmortem tissue (R. V. Sillitoe and R. Hawkes, unpublished observation). Our study thus reveals a viable approach for retrospectively characterizing possible circuitry defects underlying human diseases involving the $\mathrm{Cb}$.

\section{References}

Ahn AH, Dziennis S, Hawkes R, Herrup K (1994) The cloning of zebrin II reveals its identity with aldolase C. Development 120:2081-2090.

Apps R, Hawkes R (2009) Cerebellar cortical organization: a one-map hypothesis. Nat Rev Neurosci 10:670-681.

Armstrong CL, Krueger-Naug AM, Currie RW, Hawkes R (2000) Constitutive expression of the $25-\mathrm{kDa}$ heat shock protein Hsp25 reveals novel parasagittal bands of purkinje cells in the adult mouse cerebellar cortex. J Comp Neurol 416:383-397.

Armstrong CL, Chung SH, Armstrong JN, Hochgeschwender U, Jeong YG, Hawkes R (2009) A novel somatostatin-immunoreactive mossy fiber pathway associated with HSP25-immunoreactive purkinje cell stripes in the mouse cerebellum. J Comp Neurol 517:524-538.

Arsénio Nunes ML, Sotelo C (1985) Development of the spinocerebellar system in the postnatal rat. J Comp Neurol 237:291-306.

Arsénio Nunes ML, Sotelo C, Wehrlé R (1988) Organization of spinocere- bellar projection map in three types of agranular cerebellum: Purkinje cells vs. granule cells as organizer element. J Comp Neurol 273:120-136

Barmack NH, Baughman RW, Eckenstein FP (1992) Cholinergic innervation of the cerebellum of rat, rabbit, cat, and monkey as revealed by choline acetyltransferase activity and immunohistochemistry. J Comp Neurol 317:233-249.

Benayed R, Gharani N, Rossman I, Mancuso V, Lazar G, Kamdar S, Bruse SE, Tischfield S, Smith BJ, Zimmerman RA, Dicicco-Bloom E, Brzustowicz LM, Millonig JH (2005) Support for the homeobox transcription factor gene ENGRAILED 2 as an autism spectrum disorder susceptibility locus. Am J Hum Genet 77:851-868.

Brochu G, Maler L, Hawkes R (1990) Zebrin II: a polypeptide antigen expressed selectively by Purkinje cells reveals compartments in rat and fish cerebellum. J Comp Neurol 291:538-552.

Brunet I, Weinl C, Piper M, Trembleau A, Volovitch M, Harris W, Prochiantz A, Holt C (2005) The transcription factor Engrailed-2 guides retinal axons. Nature 438:94-98.

Chao DL, Ma L, Shen K (2009) Transient cellcell interactions in neural circuit formation. Nat Rev Neurosci 10:262-271.

Chédotal A, Bloch-Gallego E, Sotelo C (1997) The embryonic cerebellum contains topographic cues that guide developing inferior olivary axons. Development 124:861-870.

Cheh MA, Millonig JH, Roselli LM, Ming X, Jacobsen E, Kamdar S, Wagner GC (2006) En2 knockout mice display neurobehavioral and neurochemical alterations relevant to autism spectrum disorder. Brain Res 1116:166-176.

Cheng Y, Sudarov A, Szulc KU, Sgaier SK, Stephen D, Turnbull DH, Joyner AL (2010) The Engrailed homeobox genes determine the different foliation patterns in the vermis and hemispheres of the mammalian cerebellum. Development 137:519-529.

Chockkan V, Hawkes R (1994) Functional and antigenic maps in the rat cerebellum: zebrin compartmentation and vibrissal receptive fields in lobule IXa. J Comp Neurol 345:33-45.

Corrales JD, Rocco GL, Blaess S, Guo Q, Joyner AL (2004) Spatial pattern of sonic hedgehog signaling through Gli genes during cerebellum development. Development 131:5581-5590.

Corrales JD, Blaess S, Mahoney EM, Joyner AL (2006) The level of sonic hedgehog signaling regulates the complexity of cerebellar foliation. Development 133:1811-1821.

Ebner TJ, Chen G, Gao W, Reinert K (2005) Optical imaging of cerebellar functional architectures: parallel fiber beams, parasagittal bands and spreading acidification. Prog Brain Res 148:125-138.

Gharani N, Benayed R, Mancuso V, Brzustowicz LM, Millonig JH (2004) Association of the homeobox transcription factor, ENGRAILED 2, 3 , with autism spectrum disorder. Mol Psychiatry 9:474484.

Grishkat HL, Eisenman LM (1995) Development of the spinocerebellar projection in the prenatal mouse. J Comp Neurol 363:93-108.

Hashimoto M, Mikoshiba K (2003) Mediolateral compartmentalization of the cerebellum is determined on the "birth date" of Purkinje cells. J Neurosci 23:11342-11351.

Heckroth JA, Eisenman LM (1988) Parasagittal organization of mossy fiber collaterals in the cerebellum of the mouse. J Comp Neurol 270:385-394.

Ito M (2006) Cerebellar circuitry as a neuronal machine. Prog Neurobiol 78:272-303.

Joyner AL, Herrup K, Auerbach BA, Davis CA, Rossant J (1991) Subtle cerebellar phenotype in mice homozygous for a targeted deletion of the En-2 homeobox. Science 251:1239-1243. 
Kanold PO (2009) Subplate neurons: crucial regulators of cortical development and plasticity. Front Neuroanat 3:16.

Kimmel RA, Turnbull DH, Blanquet V, Wurst W, Loomis CA, Joyner AL (2000) Two lineage boundaries coordinate vertebrate apical ectodermal ridge formation. Genes Dev 14:1377-1389.

Kuemerle B, Zanjani H, Joyner A, Herrup K (1997) Pattern deformities and cell loss in Engrailed-2 mutant mice suggest two separate patterning events during cerebellar development. J Neurosci 17:7881-7889.

Larsell O (1952) The morphogenesis and adult pattern of the lobules and fissures of the cerebellum of the white rat. J Comp Neurol 97:281-356.

Logan C, Wizenmann A, Drescher U, Monschau B, Bonhoeffer F, Lumsden A (1996) Rostral optic tectum acquires caudal characteristics following ectopic engrailed expression. Curr Biol 6:1006-1014.

Manzini MC, Ward MS, Zhang Q, Lieberman MD, Mason CA (2006) The stop signal revised: immature cerebellar granule neurons in the external germinal layer arrest pontine mossy fiber growth. J Neurosci 26:6040-6051.

Marzban H, Chung S, Watanabe M, Hawkes R (2007) Phospholipase Cbeta4 expression reveals the continuity of cerebellar topography through development. J Comp Neurol 502:857-871.

Mason CA, Gregory E (1984) Postnatal maturation of cerebellar mossy and climbing fibers: transient expression of dual features on single axons. J Neurosci 4:1715-1735.

Millen KJ, Wurst W, Herrup K, Joyner AL (1994) Abnormal embryonic cerebellar development and patterning of postnatal foliation in two mouse Engrailed-2 mutants. Development 120:695-706.

Millen KJ, Hui CC, Joyner AL (1995) A role for En-2 and other murine homologues of Drosophila segment polarity genes in regulating positional information in the developing cerebellum. Development 121: 3935-3945.

Nishida K, Flanagan JG, Nakamoto M (2002) Domain-specific olivocerebellar projection regulated by the EphA-ephrin-A interaction. Development 129:5647-5658.

Oberdick J, Schilling K, Smeyne RJ, Corbin JG, Bocchiaro C, Morgan JI (1993) Control of segment-like patterns of gene expression in the mouse cerebellum. Neuron 10:1007-1018.

Ozol K, Hayden JM, Oberdick J, Hawkes R (1999) Transverse zones in the vermis of the mouse cerebellum. J Comp Neurol 412:95-111.

Sarna JR, Marzban H, Watanabe M, Hawkes R (2006) Complementary stripes of phospholipase Cbeta 3 and Cbeta 4 expression by Purkinje cell subsets in the mouse cerebellum. J Comp Neurol 496:303-313.
Schonewille M, Luo C, Ruigrok TJ, Voogd J, Schmolesky MT, Rutteman M, Hoebeek FE, De Jeu MT, De Zeeuw CI (2006) Zonal organization of the mouse flocculus: physiology, input, and output. J Comp Neurol 497: $670-682$.

Sgaier SK, Millet S, Villanueva MP, Berenshteyn F, Song C, Joyner AL (2005) Morphogenetic and cellular movements that shape the mouse cerebellum; insights from genetic fate mapping. Neuron 45:27-40.

Sgaier SK, Lao Z, Villanueva MP, Berenshteyn F, Stephen D, Turnbull RK, Joyner AL (2007) Genetic subdivision of the tectum and cerebellum into functionally related regions based on differential sensitivity to engrailed proteins. Development 134:2325-2335.

Sillitoe RV, Joyner AL (2007) Morphology, molecular codes, and circuitry produce the three-dimensional complexity of the cerebellum. Annu Rev Cell Dev Biol 23:549-577.

Sillitoe RV, Benson MA, Blake DJ, Hawkes R (2003) Abnormal dysbindin expression in cerebellar mossy fiber synapses in the $\mathrm{mdx}$ mouse model of Duchenne muscular dystrophy. J Neurosci 23:6576-6585.

Sillitoe RV, Stephen D, Lao Z, Joyner AL (2008) Engrailed homeobox genes determine the organization of Purkinje cell sagittal stripe gene expression in the adult cerebellum. J Neurosci 28:12150-12162.

Sillitoe RV, Gopal N, Joyner AL (2009) Embryonic origins of ZebrinII parasagittal stripes and establishment of topographic Purkinje cell projections. Neuroscience 162:574-588.

Sotelo C, Chédotal A (2005) Development of the olivocerebellar system: migration and formation of cerebellar maps. Prog Brain Res 148:1-20.

Udin SB, Fawcett JW (1988) Formation of topographic maps. Annu Rev Neurosci 11:289-327.

Vogel MW, Ji Z, Millen K, Joyner AL (1996) The Engrailed-2 homeobox gene and patterning of spinocerebellar mossy fiber afferents. Brain Res Dev Brain Res 96:210-218.

Wadiche JI, Jahr CE (2005) Patterned expression of Purkinje cell glutamate transporters controls synaptic plasticity. Nat Neurosci 8:1329-1334.

Wassef M, Sotelo C, Thomasset M, Granholm AC, Leclerc N, Rafrafi J, Hawkes R (1990) Expression of compartmentation antigen zebrin I in cerebellar transplants. J Comp Neurol 294:223-234.

Wurst W, Auerbach AB, Joyner AL (1994) Multiple developmental defects in Engrailed-1 mutant mice: an early mid-hindbrain deletion and patterning defects in forelimbs and sternum. Development 120:2065-2075.

Yacubova E, Komuro H (2002) Stage-specific control of neuronal migration by somatostatin. Nature 415:77-81. 